\title{
Euclidean Distance Measurement
}

National Cancer Institute

\section{Source}

National Cancer Institute. Euclidean Distance Measurement. NCI Thesaurus. Code C65170.

A generalization of the Pythagorean theorem to more than two coordinates. It is what would be obtained if the distance between two points were measured with a ruler: the "intuitive" idea of distance. 